\title{
The Description of Conformity on Junior High School Students with High Interest in Fashion
}

\author{
Rusdi Rusli \\ Psychology Department, Medical Faculty \\ Lambung Mangkurat University, \\ Banjarmasin, Indonesia \\ (dudy_abhel@yahoo.co.id)
}

\author{
Desy Noor Hadijah \\ Psychology Department, Medical Faculty \\ Lambung Mangkurat University, \\ Banjarmasin, Indonesia \\ (desynoorhadijah@gmail.com)
}

\begin{abstract}
Clothes is one of the necessities of human life that is included in the primary needs. Clothes can already be a pointer of human's lifestyle. The existence of this eventually led to the phenomenon of fashion involvement. Fashion involvement is the involvement of a person with a fashion product because of the needs, important, interests, and value of the product. Fashion involvement occurred mostly among teenagers, because of the conformity with the group of friends. Conformity is a change of behavior or belief in order to be equal to others. The purpose of this research is to know description of conformity for junior high school student with fashion involvement. The method of assessment used in this research is observation and interview. The subject of this research is a student in one of junior high school in Banjarmasin. The results of this study indicated that the subject has a high interest in fashion. The existence of this arose because of conformity with a group of friends. The factor of occurrence of such conformity is the high cohesiveness factor in the group and the number factors of the members in that group are numerous. Aspects that existed in the conformity of the subject and the group that is cohesiveness, agreement and obedience.
\end{abstract}

Keywords - conformity; fashion involvement; junior high school student

\section{INTRODUCTION}

Basic needs that are fundamental to every human being consists of the clothes, food and home. In this modern era, the human needs have been increasingly diverse, leading to difficulties in determining which are the primary needs and the secondary needs. However, among other needs, the need for food, clothes, and home are still the basic needs that must be met in order to survive [4].

Clothes are one of human primary needs. However, in addition to serve as primary needs fulfillment, clothes also serve as signal of a person's lifestyle. Currently in Indonesia, there are rapid growth with increasing trend in clothing and fashion. The impact of this growth makes people prone to follow the trend. In fact, for some people, following the trend of fashion become a necessity to appear more trendy and stylish.

Nowadays, in the province of South Kalimantan there are several shopping centers. These shopping centers provide opportunity for business in clothing and fashions, since most visitors in shopping center are looking to buy clothes. As a result, most shopping centers in South Kalimantan are selling clothes to various market segmentations. According to Indonesia Shopping Centers, fashion clothes is the main tenant type in shopping centers which sells clothing children, men and women in the form of boutiques, including accessories and cosmetics stores. In addition, based on a survey conducted by MARS in 2015 on the Study of Young Adult Behavior Indonesia showed that there were $78.9 \%$ of teenagers were buying cloth and fashion related items. After visitors of shopping centers end up buying clothes, even when it cost them a lot of money.

Reference [5] explains that for producers, teenagers are potential markets. It is due to consumption pattern is formed in this period of age. In addition, teenagers are usually easy to be persuaded by ads, they also tend to follow what their friends do, tend to be unrealistic and profligate. Those characteristic is used by some marketers to enter the teen markets.

Teens tend to have a desire to look attractive. This is done by teenagers by using clothing and accessories, such as shoes, bags, watches, and so forth that can support their appearance. Teenagers also do not hesitate to buy items to follow fashion trend because otherwise they will be considered old-fashioned, less "slangy" and not trendy. Involvement in buying clothes and other fashion related items is called fashion involvement.

According to a study conducted [2], advertising is only able to affect adolescents by $17 \%$ while $83 \%$ of adolescents are more affected by their social environment. This study is supported by research conducted [6] which state that $15.8 \%$ of buying behavior in adolescents is influenced by conformity. These facts indicate that the social environment supports influence teenagers to clothes to keep up with the latest fashion. According to [1] conformity is a behavioral adjustment to embrace the norms of the reference group, accepting the idea or group rules that govern the manner of behavior.

The purpose of this present study is to investigate the issue of conformity in junior high school students with high interest and involvement in fashion-related matters. The main development task for junior high school students is to learn, and thus it is inappropriate for them to develop consumptive and excessive. In addition, excessive consumption should be not in their priority, let alone their limitation of financial 
matters. Unfortunately, social environment plays a significant role in formation of fashion involvement attitude. Such issue arises in participants who attend elite school where most of the students come from middle to upper economic class. Circumstances of being a member of middle to upper economic class family facilitate students to buy the latest fashion. In addition, being educated in elite school where most students come from middle to upper economic class create condition of which students need to conform with the other students, in this case, in terms of fashion. Moreover, social media factors are now facilitating teenagers with fondness in fashion.

\section{METHOD}

\section{A. Participants}

Participants of in this study are Junior high school student in Banjarmasin.

\section{B. Data Collection}

Data was collected using observation and interview which aim to understand why participants conform to their friends and to describe their fashion involvement. Participants were asked to answer a list of questions constructed by investigator provided by the researchers about conformity and fashion involvement.

\section{RESULTS}

The result of this study is:

a. Participants have high interest in fashion since they started junior high school and were influenced by their peers.

b. Participants' conformity to their group of friends are influenced by high cohesiveness in the group and the number of members in the group consist of considerable members.

c. Conformity creates normative influence of which participants try to adjust with their group of friends to be accepted. In addition, group of friends also provide an informational influence which make participants perceive that their friends have extensive knowledge in the fashion and thus make participants are motivated to know more about fashion.

d. The first aspect is conformity aspects that exist in the form of cohesiveness that materialized into behavior of participants and their group of friends who loves to buy new clothes and keeping up with the latest fashion trends. Because they have the same interest, this end up with increased cohesiveness between participants and their group of friends. The second aspect is an agreement whereby participants and their group of friends have unwritten agreement regarding their taste of fashion. The last aspect is obedience where participants obey everything in their group, not out of fear of threat or punishment, but because of their own wishes to meet the expectations of other members in their group.

e. The form of conformity is in the form of acceptance of which participants received everything in their group of friends with pleasure, not because of coercion.

\section{DISCUSSION}

This study aims to know the description of conformity in a junior high school student who has high fashion involvement. The results show that these students have a high interest in fashion because of the conformity with her peers in school. The conformity of the subject and group of friends is due to the presence of a high cohesiveness in the group and the number of members in the group consists of considerable members.

The conformity factors found in this study are similar to the theory put forward [1]. These factors are divided into three types: cohesiveness, group size and descriptive social norms injunctive social norms. Cohesiveness is defined as the level of interest that individuals perceive to a certain group. The second factor is group size associated with number of member in a group. The more members joined in the group will increase conformity. The latter is a descriptive social norm and an injunctive social norm. Descriptive norms describe what most people do in certain situations. These norms influence behavior by telling us what is generally considered effective or adaptive to the situation. Instead, the injunctive norm determines what to do, what behavior is accepted or not accepted in a particular situation. Based on the results of interviews with the participants, it is found that factor that creates conformity in the group is group cohesiveness number of members in their group of friends. Participants state that they are always interested in the group when they discuss the latest information about fashion, discuss about the latest clothing models, discuss fashion show events featuring favorite models of participants and their friends. The conversation makes participants more pleased and interested in being member of the group.

According the theory [3], there are three aspects of the existing conformity. These aspects are cohesiveness, agreement and obedience. The cohesiveness aspect concerned with adjustment and attention to the group. The agreement aspect is the opinion of the reference group that has been made to have strong pressure so that the teenager should be loyal and adjust his opinion with the opinion of the group. The agreements themselves relate to beliefs, shared opinions, and deviations from group opinions. The last aspect of conformity is that of obedience. The pressure or demands of the benchmark group on teens make it willing to take action even when the teenagers do not want it. If obedience is higher than the conformity will be high as well. Self-obedience is linked to pressure due to rewards, threats, or punishments and expectations of others. Conformity aspects that exist on the subject and friends of a group is the cohesiveness that materialized with the behavior of subjects and friends of a group who both love to buy new clothes and find out the latest fashion developments that make the cohesiveness of the subject and the group becomes more and more tightly. The second aspect is an agreement whereby the subject and his group have unwritten agreements about their likes in fashion. The last aspect is obedience where the subject obeys all things in his group not out of fear of threat or punishment, but the subject does so because of his own wishes and wants to meet the expectations of other members in his group. 


\section{IMPLICATION AND RECOMMENDATION}

As already discussed, fashion involvement is less suitable if it occurs in teenagers especially who do not have their own income where it can lead to consumptive behavior and improvidence. Therefore, the teenagers should be able to control him not to shop clothes in excess. In addition, the subject should also be able to take advantage of money given by his mother for things other than clothing. Subjects can begin to seek interest in anything other than fashion such as trying out music lessons or exercising with their friends.

For families or other people who have children with similar behaviors such as this study should be able to help the child by providing understanding or advice about fashion involvement so that the concerned is not focused with the interest he has. In addition, parents are expected not to spoil their children too much and do not give all that the child wants freely without thinking about the impact on the child. Because it can have a negative impact for the children themselves.

Suggestions for future study is to be able to dig deeper about the conformity that is formed because of fashion involvement and look for the subject of age or education level that is more diverse considering this research is still limited only to junior high school students. Future studies should try to find more subjects and from a wide range of age ranges to get more accurate research results.

\section{REFERENCES}

[1] Baron, R.A., and Byrne, D. (2005). Social Psychology Vol. 2. 10th Edition. Interpreting: Ratna Djuwita. Jakarta: Erlangga.

[2] Cahyani, Y. (1995). Advertising, Television, and Urban Adolescent Behavior. Airlangga University. Surabaya. Unpublished research.

[3] Sears, D. O. (2009). Symbolic racism. In J. M. Levine and M. A. Hogg (Eds.). Encyclopedia of Group Processes and Intergroup Relations. Thousand Oaks: Sage.

[4] Suryana, A. (2001). Kebijakan Ketahanan Pangan Nasional (Online). http://pse.litbang.deptan.go.id. Accessed on Thursday, September 29, 2016

[5] Tambunan, R. (2001). Youth and Consumtive Behavior. http://www.epsikologi.com. Accessed on Thursday, September 29, 2016.

[6] Zebua, A.S, Nurdjayadi, R.D. 2001. Relationship between Conformity and Self-Concept with Consumer Behavior in Young Women. Journal of Applied Psychology: Phronesis, 3 (6). 